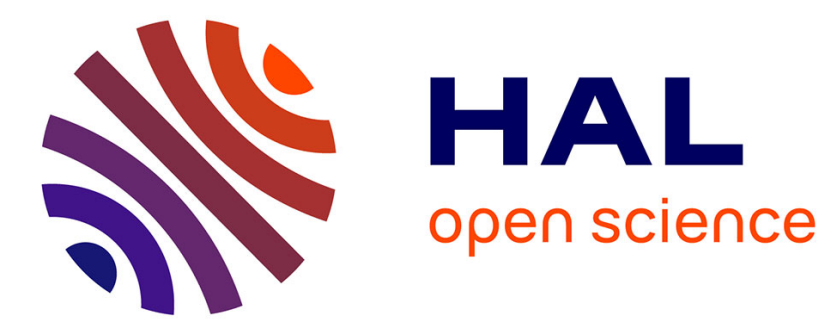

\title{
Isothermal nitridation kinetics of TiSi2 powders
}

\author{
Jérôme Roger, L Maillé, Marie-Anne Dourges
}

\section{To cite this version:}

Jérôme Roger, L Maillé, Marie-Anne Dourges. Isothermal nitridation kinetics of TiSi2 powders. Journal of Solid State Chemistry, 2014, 212, pp.134-140. 10.1016/j.jssc.2014.01.021 . hal-01323667

\section{HAL Id: hal-01323667 https://hal.science/hal-01323667}

Submitted on 2 Jun 2016

HAL is a multi-disciplinary open access archive for the deposit and dissemination of scientific research documents, whether they are published or not. The documents may come from teaching and research institutions in France or abroad, or from public or private research centers.
L'archive ouverte pluridisciplinaire HAL, est destinée au dépôt et à la diffusion de documents scientifiques de niveau recherche, publiés ou non, émanant des établissements d'enseignement et de recherche français ou étrangers, des laboratoires publics ou privés. 


\title{
Isothermal nitridation kinetics of $\mathrm{TiSi}_{2}$ powders
}

J. Roger*, L. Maillé, M.A. Dourges

Université de Bordeaux, CNRS, Laboratoire des Composites ThermoStructuraux, UMR 5801, 33600 Pessac, France

* Corresponding author: e-mail: roger@lcts.u-bordeaux1.fr, phone number: +33 5568447 36, fax number: +33556841225

\begin{abstract}
The aim the present work is to determine the reaction kinetics between a $\mathrm{TiSi}_{2}$ powder with gaseous nitrogen. Isothermal nitridation of $\mathrm{TiSi}_{2}$ powders with fine $(1.4 \mu \mathrm{m})$ and medium $(4.5 \mu \mathrm{m})$ particle size has been studied in pure nitrogen atmosphere ranging from 1000 to $1200^{\circ} \mathrm{C}$ for duration up to 50 hours. The isothermal nitridation kinetics of $\mathrm{TiSi}_{2}$ powders were investigated by thermogravimetry. The nitridation rate strongly depends on the particle size and temperature. The smaller particle size exhibits the higher nitridation rate due to its larger surface area. The conversion process is complex with nucleation and growth of $\mathrm{TiN}$ at the surface of the grain and $\mathrm{Si}_{3} \mathrm{~N}_{4}$ inside the grain promoted by Kirkendall effect with an influence of the volume increase.
\end{abstract}

Keywords: nitridation; kinetic law; isothermal; powder; nucleation. 


\section{Introduction}

During the last decades, important progress has been made in the development of engineering ceramic materials, particularly the technical ceramics which are expected to be used in the structural components for high temperature applications. Previously, the synthesis of silicon nitride $\mathrm{Si}_{3} \mathrm{~N}_{4}$ by the reaction between silicon and nitrogen has received much attention in the attempt to exploit the high-strength, heat-resistant properties of this material [1-7]. One of the attractive methods for the synthesis of $\mathrm{Si}_{3} \mathrm{~N}_{4}$ ceramics is the nitridation of silicon powder compacts but this requires high temperatures treatments and induces a relative low volume increase of only $21.6 \%$. The effects of the main controlling factors on the nitridation of silicon powders were examined in several previous studies: temperature [8-10], particle shape and size [8], impurities in the sample and in the atmosphere [11-13], composition of the atmosphere $[14,15]$. On this way, synthesis of silicon nitride and titanium nitride phases by direct nitridation of a $\mathrm{TiSi}_{2}$ powder has the advantage to generate of more economical generation a ceramic. Indeed, $\mathrm{TiN}-\mathrm{Si}_{3} \mathrm{~N}_{4}$ composites represent an interesting combination with specific properties: high strength, low density, electrical conductivity [16]. This kind of composite can be easily obtained by self-propagating high temperature synthesis (SHS) under nitrogen atmosphere [17]. Previous studies undertaken on the nitridation of $\mathrm{TiSi}_{2}$ powders demonstrated that the nitridation of this compound is a two stepped mechanism [18-20]. The influence of the temperature factor was also reported with a noticeable acceleration of the kinetics above $1100^{\circ} \mathrm{C}$. Up to now, the observed limitations of this process were not clearly identified and no evaluation of the kinetic variations with temperature was made [20]. It was then especially interesting to realize our experiments around $1100^{\circ} \mathrm{C}$. At this relative low temperature, the main difficulty is the requirement of long time for complete nitridation [2123]. According to the Ti-Si-N phase diagram at $1100^{\circ} \mathrm{C}$ (Fig. 1) from Ma et al. [24], the 
complete nitridation of the initial powder leads to the formation of $\mathrm{TiN}$ and $\mathrm{Si}_{3} \mathrm{~N}_{4}$ phases according to the Reaction [1]:

$$
6 \mathrm{TiSi}_{2}+11 \mathrm{~N}_{2} \Rightarrow 6 \mathrm{TiN}+4 \mathrm{Si}_{3} \mathrm{~N}_{4} \quad[1]
$$

This reaction would occur by a theoretical weight gain of $50 \%$ and a theoretical volume gain of 59\% [24]. Extensive and complete studies of the kinetic analysis of silicon nitridation were previously realized and would be compared with titanium silicide nitridation $[13,25]$. So, the purpose of the present work is a study of the nitridation mechanism and kinetic of $\mathrm{TiSi}_{2}$ powders with different grain sizes. In order to examine the effect of time and temperature parameters, the study was performed under normal atmosphere of $\mathrm{N}_{2}$ at different temperatures between 1000 and $1200^{\circ} \mathrm{C}$ for durations up to 50 hours.

\section{Materials and experimental procedures}

The $\mathrm{TiSi}_{2}$ powder $(99.95 \%, 44 \mu \mathrm{m}$, Neyco) used in these experiments was analyzed by spectrographic analysis (S.C.A.-C.N.R.S., Villeurbanne, France) to contain $1.64 \%$ O, $0.43 \%$ $\mathrm{C}$ and $0.48 \% \mathrm{Fe}$ in mass. The presence of some percents of iron is known as having a catalytic effect on Si reactivity [26]. Due to the very low quantity of iron in the $\mathrm{TiSi}_{2}$ powder and the relative low working temperature we could consider it as having a negligible effect. The raw powder was milled by two different ways: with a vibratory mixer mill (Retsch MM200), or with a planetary ball mill (Fritsch Pulverisette 7). By these ways, two types of powders were obtained and used in the present work. The powders exhibit the following characteristics: $\mathrm{d}_{50}=4.5 \mu \mathrm{m}, \mathrm{d}_{90}=10 \mu \mathrm{m}$ for the powder milled with a vibratory mill and $\mathrm{d}_{50}=1.4 \mu \mathrm{m}, \mathrm{d}_{90}=1.9 \mu \mathrm{m}$ for the powder milled with a planetary ball mill. The grain size distributions of the powders were determined with the help of a Fritsch Analysette 22 Nanotec plus granulometric analyser. The mass variation measurements were performed in a thermogravimetric analyzer 
(Setaram TAG24) by heating from $20^{\circ} \mathrm{C}$ to the treatment temperature at a heating rate of $10^{\circ} \mathrm{C} / \mathrm{min}$ by applying the isothermal treatment for various durations up to 50 hours. The measurements of mass gain at $1150^{\circ} \mathrm{C}$ and $1200^{\circ} \mathrm{C}$ were limited to 12.5 hours of nitridation because of technical limitations due to the volatility of silicon. Moreover, weight gains of about $30 \%$ were estimated as sufficient for a kinetic analysis. The two kinds of nitridation experiment were realized at normal pressure under a continuous nitrogen gas flow $(50 \mathrm{~mL} / \mathrm{min})$ to have a nitrogen excess. The experimental deviation of mass variation was estimated to be about $0.5 \%$. The gaseous nitrogen used contains $2 \mathrm{ppm}$ of oxygen as impurity, what was considered as having a low impact on the experiments. The powder masses used for thermogravimetric analysis were comprised between 100 and $110 \mathrm{mg}$ for each sample, the mass conversion degree $(\alpha)$ of reaction at a time $t$ was estimated according to Equation 1:

$$
\alpha=\frac{\left(w_{i}-w_{0}\right)}{\left(w_{f}-w_{0}\right)}
$$

where $w_{0}, w_{\mathrm{i}}, w_{\mathrm{f}}$ are the initial, intermediate and final sample masses for complete conversion of $\mathrm{TiSi}_{2}$ according to Equation 1 . Some powders were also treated in a tubular furnace at 1000 or $1100^{\circ} \mathrm{C}$ in order to obtain sufficient quantities of matter for $\mathrm{X}$-ray diffraction (XRD) measurements. Indeed, these diffraction experiments were used for phase identification and quantitative phase determination in samples of sufficient size $(200 \mathrm{mg})$ which permitted accurate powder diffraction profiles to be obtained [27]. Each pattern was analyzed using the Rietveld [28] whole profile fitting method with the software Fullprof [29]. XRD experiments in Bragg-Brentano geometry were performed with a Bruker D8 Advance diffractometer using a $\mathrm{Cu} \mathrm{K} \alpha$ radiation fitted with a one-dimensional position sensitive silicon strip detector (Bruker, Linxeye). XRD patterns were recorded using a step size of $0.01^{\circ}$ for $2 \theta$ range $10-90^{\circ}$ and a counting time of 0.3 second per step. Sections of nitrided $\mathrm{TiSi}_{2}$ grains were prepared using ion polishing system (Cross Polisher JEOL Ltd.). These sections are observed with a FEI Quanta 400 FEG scanning electron microscope whereas the chemical composition is 
analyzed by EDX (EDAX Genesis XM4), operated at $5 \mathrm{kV}$ (interaction volume of roughly $150 \mathrm{~nm}$ wide in this condition).

\section{Results and discussion}

\subsection{Effect of temperature and grain size on the nitridation}

Figures 2 and 3 shows the conversion curves $\alpha=f(t)$ obtained from thermogravimetric analyses on the two powders at nitridation temperatures of 1000,1050,1075, 1100, 1150 and $1200^{\circ} \mathrm{C}$. From these figures it appears that the particle size and the operating temperature have noticeable effects on the reaction kinetic of $\mathrm{TiSi}_{2}$ with nitrogen. Faster reaction rates and greater overall conversions are generally observed with increasing temperature. Atkinson et al. [30] carried out nitridation of silicon at temperatures between 1523 and $1633 \mathrm{~K}$. Their results also indicated that a higher conversion rate was obtained by increasing temperature. Pigeon and Varma [31] reported the same tendency during the nitridation of silicon in the range from 1473 and $1623 \mathrm{~K}$. In Figures 2 and 3, all curves have the same shape. Indeed, the initial part of the curves is approximately linear with high slopes, and the latter part is approximately parabolic. This illustrates the fact that the formation of a nitride layer during the reaction rapidly covers the grain surface and consequently decreases the reaction rate. This phenomenon is observable in the Figure 4-a) where a thin layer of $\mathrm{TiN}$ is formed at the entire surface of the gain after only a nitridation at $1100^{\circ} \mathrm{C}$ during $5 \mathrm{~h}$. But after a heating of 50 hours, $\mathrm{Si}_{3} \mathrm{~N}_{4}$ nucleates inside the grain thanks to porosities promoting the interaction between silicon and gaseous nitrogen within the grain as shown in the Figure 4-b). The porosities are due to a Kirkendall effect because of the faster diffusion of titanium to the surface of the grain. The values of the conversion rate $\alpha$ after 10 hours of nitridation are given

in Table 1. It is clear that increasing temperature and decreasing the grain size promote the 
conversion into nitrides. This is not really surprising by considering the fact that finer powders also have larger specific surface areas per mass unit, what improves the interaction between $\mathrm{TiSi}_{2}$ and nitrogen and induce an increase of apparent reaction rates. This kind of behavior has already been reported previously about the nitridation of silicon powders [3133]. It is worth noting that all the values of $\alpha$ for the coarser powder are lower than the corresponding ones for the finer powder except the value at $1200^{\circ} \mathrm{C}$. This behavior at $1200^{\circ} \mathrm{C}$ could be explained by a limitation of the reaction at the bottom of the powder. After 10 or 50 hours of nitridation, the conversion rates are relatively low at any temperatures and far from the full conversion. The best values in each case are obtained at $1200^{\circ} \mathrm{C}$ after 12.5 hours of nitridation leading to interesting values equal to $81.8 \%$ and $60.9 \%$ for the coarser powder and for the finer one, respectively. Half conversion rate is only attained after 10 hours for samples heated at 1150 and $1200^{\circ} \mathrm{C}$.

\subsection{Isothermal nitridation kinetics analysis}

Three types of kinetic models can be proposed for solid state reactions corresponding to three main mechanisms [34]:

1) controlling step is diffusion of reactants or diffusional models,

2) administrated mechanism is chemical reaction at the interphase of reactant-product,

3) reaction rate is determined by nucleation and growth.

In order to identify the appropriate reaction mechanism, the classic kinetic models were tested to the experimental $\alpha=g(t)$ curves [35,36]. Among these kinetic models, no one was able to fit correctly the curves. The initial quasi-linear shape is approximately described by an Avrami-Erofeev model (A2) corresponding to a one- or two-dimensional growth of nuclei. The equation of this model is expressed by the Equation 2:

$$
k^{\prime} \cdot t=[-\operatorname{Ln}(1-\alpha)]^{1 / 2}
$$


with $t$ the time and $k^{\prime}$ the reaction rate constant. Figure 5 shows the variation of the calculated $k^{\prime}$ factors with temperature for the two powders. First, it can be noticed that the $k^{\prime}$ coefficients are higher for the finer powder. The values increase regularly with temperature between 1050 and $1150^{\circ} \mathrm{C}$. But stronger variations are observed between 1000 and $1050^{\circ} \mathrm{C}$ and between 1150 and $1200^{\circ} \mathrm{C}$. In the first case, there is a stronger increase whereas in the second case there is an unexpected decrease. The durations of the steps are nearly equal to 30 minutes between 1000 and $1150^{\circ} \mathrm{C}$ in the both cases. Their durations are higher at $1200^{\circ} \mathrm{C} ; 40$ minutes for the powder with the higher granulometry and 80 minutes for the finer one. This step corresponds to the speedy formation of a continuous layer of $\mathrm{TiN}$ at the surface of the grain but with a variation of the mechanism probably induced by an evolution of the phenomenon limiting the reaction. Finally, the use of the Johnson-Mehl-Avrami (JMA) equation was found appropriate to determine the kinetics of the decelerating part of the curves, which defines the conversion limitation [37-38]. So, our examination is mainly focused on this stage. The JMA model describes a wide variety of isothermal solid state transformations and it is helpful to determine the characteristics of nucleation-growth processes $[39,40]$. The JMA model is relevant for homogeneous or heterogeneous nucleation at randomly dispersed second phase particles and the growth rate of this new phase is controlled by temperature and is dependant upon time, what is in good agreement with the observations made on the grains [41]. Hence, the JMA model was applied for modeling the kinetic of the second part of the conversion process. The equation corresponding to the JMA model expresses the fact that conversion mechanisms depend on a broad variety of solid state reactions; it is expressed by Equation 3 [42]:

$$
\alpha(t)=1-e^{-(k t)^{n}}
$$

where $t$ is time, $n$ the Avrami exponent which depends on the growth mechanism and the geometry of powder [42]. The value of $n$ depends on the conversion mechanisms involved 
during the phase transformation, providing that the phase conversion proceeds by nucleation and growth models [43]. $k$ is the reaction rate and is constant for a given temperature. Hence, the values of $n$ and $k$ depend on the kind of reaction mechanisms which control the transformation. Equation 3 is generally used to evaluate experimental data by means of a logarithmic plot of $\operatorname{Ln}[-\operatorname{Ln}(1-\alpha)]$ versus $\operatorname{Ln}(t)$. This curve is called the Avrami plot. The slope and intercept of the resulting straight line are $n$ and $n \cdot \operatorname{Ln}(k)$, respectively. Avrami plots of each sample are shown in Figure 6. The slightly deviation from linearity observed particularly on the curves at temperatures higher than $1100^{\circ} \mathrm{C}$ for the $\mathrm{d}_{50}=4,5 \mu \mathrm{m}$ can be explained by the grain size dispersion. The calculated values of $n$ and $k$ are listed in Table 2. All the values of $n$ are less than 2.5, which indicates that the nucleation-growth process is limited by the diffusion within the grain [44-46]. Also, at any constant temperature the values of $n$ and $k$ increase by increasing milling efficiency. The apparent activation energy of transformation was calculated using the Arrhenius equation of reaction rate constant in the logarithmic form:

$$
\operatorname{Ln} k=\operatorname{Ln}_{0}-\frac{E_{\mathrm{a}}}{R \cdot T}
$$

where $k_{0}$ is a constant called frequency factor, $E_{\mathrm{a}}$ is the apparent activation energy, $R$ is the gases constant, $T$ is the absolute temperature. Figure 7 displays the variation of $\operatorname{Ln}(k)$ as a function of $1000 / T$ for each sample. $E_{\mathrm{a}}$ is determined from the slope of lines in each temperature range. The estimated values of apparent activation energy of the nitridation reaction in various conditions are listed in Table 3. Figure 7 shows changes of the slopes around $1100^{\circ} \mathrm{C}$ for the two kinds of powder. The diminution of the slopes reveals a modification of the nitridation mechanism at this temperature. The apparent activation energies are nearly the same below $1100^{\circ} \mathrm{C}$ with values equal to $964.33 \mathrm{~kJ} \mathrm{~mol}^{-1}$ for the powder with $d_{50}=1.4 \mu \mathrm{m}$ and $920.82 \mathrm{~kJ} \cdot \mathrm{mol}^{-1}$ for the powder with $\mathrm{d}_{50}=4.5 \mu \mathrm{m}$. It can be deduced that the nucleation-growth mechanism is the same in both cases. At temperatures higher than $1100^{\circ} \mathrm{C}$, the activation energies are lower than below $1100^{\circ} \mathrm{C}$ and the value with 
the finer powder is half of the value for the other powder, the values being equal to 245.13 $\mathrm{kJ} . \mathrm{mol}^{-1}$ and $594.45 \mathrm{~kJ} \cdot \mathrm{mol}^{-1}$, respectively. This important difference can only being attributed to the different kind of milling, whereas there is no evidence of such an effect below $1100^{\circ} \mathrm{C}$. This demonstrates that decreasing the grain size of the powder influences the reaction mechanism at the higher temperatures. Nevertheless, the values of the frequency factors $k_{0}$ given in Table 4 indicate that the frequency factor of the finer powder is a little higher below $1100^{\circ} \mathrm{C}$ comparing to the other powder. The same remark is applicable to the values of the Avrami coefficients $n$ (Table 2). The values of the Avrami coefficients are lower than the values expected in classical cases, comprised between 1.5 and 4 . The range of calculated values for $n$ is comprised between 0.150 and 0.765 , it was previously identified for complex mechano-chemical syntheses $[47,48]$. In the present case, this is probably induced by the Kirkendall effect which generates complex solid-gas diffusion phenomenon. Despite the difficulties to interpret the values from the JMA theory, this result tends to confirm the fact that decreasing the grain size promotes the reaction by increasing the number of nucleationgrowth sites, the apparent activation energy staying the same. In both cases, a decrease of the frequency factor values is observed above $1100^{\circ} \mathrm{C}$. The variation is particularly noticeable for the finer powder. As a consequence, above $1100^{\circ} \mathrm{C}$, the decrease of the apparent activation energy of the finer powder could promote the reaction but in the same time the strong decrease of the frequency factor indicates a great limitation of the reaction. It could be considered that this limitation is attributable to a rapid decrease of the porosity into the powder and/or to the formation of a coating at the surface of the sample. The mass percentage variations of the different phases during nitridation at 1000 and $1100^{\circ} \mathrm{C}$ for durations up to 100 hours are given in Figure 8, they were measured X-ray diffraction and Rietveld analysis on powders heat treated in tubular furnace. Those analyses were based in each case on a unique sample by successive samplings and by incrementing the heating times. Between each 
sampling, the samples were homogenized by crushing. By this way the nitridation cannot be limited by gas diffusion. The mass variations of all the phases identified $\left(\mathrm{TiSi}_{2}, \mathrm{Si}, \mathrm{TiN}\right.$ and $\mathrm{Si}_{3} \mathrm{~N}_{4}$ ) are given in the Figure 8. It appears that the $\mathrm{TiSi}_{2}$ reaction kinetic is obviously higher for the smaller particles. It is also clear that the nitridation of titanium is easier than the nitridation of silicon. Indeed, even if the kinetics depend on temperature and grain size, in all cases the TiN mass percentages reach rapidly high values of about $50 \%$. Contrarily to the nitridation of silicon that appears very slow since the reached values after some dozen of hours are less than $10 \%$ in mass, except at $1100^{\circ} \mathrm{C}$ for the finer powder but after several dozens of hours of treatment. From those results, it can be deduced that in all cases the nitridation of $\mathrm{TiSi}_{2}$ powders proceeds in two processes corresponding to the rapid nitridation of titanium by forming TiN at the surface of the grain and to the slow nitridation of silicon by forming $\mathrm{Si}_{3} \mathrm{~N}_{4}$ within the grain. These results agree well with the observations realized about the nitridation of $\mathrm{TiSi}_{2}$ by Córdoba et al. [20]. The kinetics of these steps strongly depend on the temperature but also on the grain size. In the first times, the formation of $\mathrm{TiN}$ is the predominant reaction. This is not the case for the formation of $\mathrm{Si}_{3} \mathrm{~N}_{4}$ even if its formation is accelerated by higher temperatures. The use of smaller powders facilitates the reaction between silicon and nitrogen especially at $1100^{\circ} \mathrm{C}$ so much so that free silicon is no more detectable by X-ray diffraction experiments after 50 hours at $1100^{\circ} \mathrm{C}$. In the same time, the cumulative mass fractions of $\alpha-\mathrm{Si}_{3} \mathrm{~N}_{4}$ and $\beta-\mathrm{Si}_{3} \mathrm{~N}_{4}$ reaches a total of 51.4 mass $\%$ which is a value largely higher than the other ones obtained for this duration. The corresponding value for the powder with the higher grain size is only of 16.1 mass $\%$ with 33.3 mass $\%$ of silicon. It should be remarked that the finer powder heated at $1100^{\circ} \mathrm{C}$ during 100 hours is practically fully converted. Indeed, it contains $44.0 \%$ of $\mathrm{TiN}$ and $56 \%$ of $\mathrm{Si}_{3} \mathrm{~N}_{4}$ in mass, the full conversion leading to a mass ratio of 40/60. This result is largely higher than the corresponding TGA sample which exhibits only a conversion rate equal to $60 \%$. This 
difference can be justified by the fact that the powders used for the X-ray analyses were homogenized by crushing between each sampling in order to promote the powder/gas interaction.

\subsection{Kinetic model of $\mathrm{TiSi}_{2}$ powders nitridation}

The nitridation process of $\mathrm{TiSi}_{2}$ can be partially compared to the nitridation behavior of silicon powders studied by Pigeon and Varma [13]. In their work these authors demonstrate that the nitridation of silicon consists of a reaction-bonding process divided into three stages. During the first stage, silicon exposed at the surface of the powder is converted into silicon nitride nuclei which are at the origin of a seeding effect inducing the second stage with a fast and massive nitridation rate. During this second stage, nitrogen is able to diffuse freely in the macropores. However, the volume gain induced by the particle nitridation decreases the permeability and consequently slows down the conversion kinetics, what corresponds to the third stage of the silicon conversion process. Nitridation of $\mathrm{TiSi}_{2}$ is more complex because of the presence of titanium that influences the nitridation kinetics of silicon. The main difference between the present study and the one of Pigeon et al. [13] is that the nitridations of titanium and silicon are obtained by different mechanisms. Moreover, full nitridation of $\mathrm{TiSi}_{2}$ is characterized by a volume gain equal to 59\%. Compared to the corresponding value for pure silicone that is $21 \%$, the volume increase during $\mathrm{TiSi}_{2}$ conversion is very larger and could generate a decrease of the permeability of the powder and consequently an intense slowdown of the mass gain. This is the situation identified for the finer powder from $1100^{\circ} \mathrm{C}$. According to the experimental observations, the reaction between $\mathrm{TiSi}_{2}$ and nitrogen is composed of two main steps with different rates: the first one is mainly attributable to the rapid formation of a continuous TiN layer at the surface of the grains; the second step is slower. As the thickness of the TiN layer gradually increases, the nitridation rate decreases and the nucleation-growth 
reactions are mainly controlled by diffusion. Concretely, silicon atoms cannot react with nitrogen because of the formation of the TiN layer, they react thanks to the formation of Kirkendall porosities that promote the diffusion of nitrogen molecules and their reaction with silicon atoms inside the grains. This conversion mechanism is complex and involves two different chemical reactions at different times and locations and by different ways as represented in the Figure 9. Thermal and milling activations increase Avrami exponent and reduce diffusion barriers effect, except at 1150 and $1200^{\circ} \mathrm{C}$ (Table 2). Indeed, lowering the grain size by milling increases the surface area and the structural defect, what accelerates the conversion [6]. Hence, larger number of nucleation sites and shorter diffusion routes enhance the nitridation reaction. Above $1100^{\circ} \mathrm{C}$, the Avrami coefficients are notably lower for the finer powder. This is attributable to the apparition of a limitation for this powder at the highest temperatures because of the rapid formation of a dense layer at the surface of the powder obtained by volume increase. In fact, decreasing grain size promotes the reaction but in the same time the reaction occurs essentially at the surface of the powder. This volume gain influences the kinetic by obstructing the macroporosities between the grains, as reported by Pigeon and Varma. Therefore, the diffusion of nitrogen is made more difficult and leads up to an inhomogeneous nitridation of the whole powder. By this way, reducing grain size is deleterious for temperature above $1100^{\circ} \mathrm{C}$. Analysis of the results also proposes that the phase conversion could partially depend on a powder-gas interface controlled growth [14,24].

This mechanism can be detailed as follows:

a) nitrogen molecules are chemisorbed onto the powder surface. Nuclei of titanium nitrides are formed on the grains surface in the initial stage of the nitridation,

b) titanium atoms diffuse to the surface of the nuclei to continue the nitridation reaction. A continuous layer composed of TiN is gradually formed at the surface of the grains, as shown on Figure 4-a), 
c) when the TiN layer has thickened to cover the grain surface completely, the reaction rate decreases and is controlled by the diffusion of titanium and nitrogen through the TiN layer. In the same time,silicon begins to react with gaseous nitrogen infiltrated in the grain (Fig. 4-b)). Owing to volume increase, those reactions are also dependent upon the gas diffusion in the macroporosities of the powder that can be reduced at the surface.

As already expressed, the nitridation of titanium is the faster reaction and consequently is predominant. At the last stage, the conversion rate is relatively low but strongly depends on the particle size. Indeed, a reduction of the mean size of the powder makes possible to reach a conversion rate largely higher because of a more important area of contact between powder and the gas and also because of a reduction of the diffusion distances. In our case, this effect appears to be insufficient to reach rapidly a full conversion. As reported by Pigeon et al. [13], the compact effects dominate with the formation of a dense product layer on the outer side of the powder. The full conversion is consequently difficult in the case of large sized samples. More clearly, the global conversion rate and the final conversion value also depend on the quantity of matter to react.

\section{Conclusion}

The purpose of this study is to identify chemical mechanisms and the effect of temperature and grain size on the nitridation of $\mathrm{TiSi}_{2}$ by pure nitrogen at temperatures comprised between 1000 and $1200^{\circ} \mathrm{C}$ for durations up to 50 hours. Nitridation behavior of $\mathrm{TiSi}_{2}$ powders has been evaluated by kinetics investigations. The degree of nitridation strongly depends on both temperature and grain size. X-ray powder diffraction indicated that the nitridation of titanium to TiN is clearly the fastest phenomenon at any temperatures. This nitride forms a continuous layer at the surface of the grain. Nitridation of silicon is slower and highly dependent upon the temperature and grain size. This nitride is formed within the grain via a Kirkendall effect 
which promotes the reaction between silicon and gaseous nitrogen. So, the nitridation kinetic of $\mathrm{TiSi}_{2}$ powders exhibits two processes with a rapid crystallization of $\mathrm{TiN}$ at the surface of the grain accompanied and substituted in time by a slow nucleation-growth process of $\mathrm{Si}_{3} \mathrm{~N}_{4}$ in the grain that obeys to the Johnson-Mehl-Avrami model. For the two powders, the activation energies were estimated. In any cases, the full nitridation is not reached even for long time treatments. The $\mathrm{TiSi}_{2}$ powders nitridation process can be described by three different steps:

a) Nuclei of TiN are rapidly formed on the grains surface in the initial stage of the nitridation.

b) A product layer of $\mathrm{TiN}$ is gradually formed at the surface of the grains by diffusion of titanium and nitrogen.

c) TiN synthesis decreases because of a thickened layer of products that completely covers the grain surface. In the same time, owing to Kirkendall porosities, free silicon can react with nitrogen coming from porosities. This mechanism is particularly complex and its kinetic is generally low.

The difficulty to reach a homogeneous and full conversion also comes from a lowering of the powder permeability because of the high volume increase which generates a noticeable limitation to gaseous nitrogen diffusion. This effect is largely influenced by temperature and grain size. A decrease of the grain size and an increase of temperature promotes a rapid and a high level of nitridation especially at the surface of the powder. This limits the interest of using low grains-sized at high temperature because the grains at the top of the powder react rapidly contrary to the grains at the bottom. The main inconvenient is a possible sealing at the top of the powder preventing its homogeneous conversion. The research of solutions to promote and to facilitate the full and homogenous conversion should be shortly examined.

\section{Acknowledgement}


The authors wish to express their thanks to Pr. Yann Le Petitcorps, from the University of Bordeaux, for his scientific assistance and for critical reading of the manuscript. Thanks go also to Christine Picard for all her technical assistance and TGA measurements. 


\section{References}

[1] H. Lange, G. Wötting, G. Winter, Silicon nitride-From powder synthesis to ceramic materials, Angew. Chem. Int. Ed. Engl. 30 (1991) 1579-1597.

[2] F. Riley, Preparation and properties of silicon nitride based materials, Mater. Sci. Forum 47 (1989) 70-83.

[3] H.M. Jennings, B.J. Dalgleish, P.L. Pratt, Reactions between silicon and nitrogen, J. Mater. Sci. 23 (1988) 2573-2583.

[4] G. Ziegler, J. Heinrich, G. Wötting, Relationships between processing, microstructure and properties of dense and reaction-bonded silicon nitride, J. Mater. Sci. 22 (1987) 30413086.

[5] H.M. Jennings, On reactions between silicon and nitrogen, J. Mater. Sci. 18 (1983) 951967.

[6] A.J. Moulson, Reaction-bonded silicon nitride: its formation and properties, J. Mater. Sci. 14 (1979) 1017-1051.

[7] M.J. Hoffmann, G. Petzow, Silicon Nitride Ceramics Scientific and Technology Advances, in: I.W. Chen, P.F. Belcher, G. Petzow, T.S. Yeu (Eds.), Materials Research Society Microstructure design of $\mathrm{Si}_{3} \mathrm{~N}_{4}$ based ceramics, Pittsburgh, 1993, pp. 3-14.

[8] A. Atkinson, P.J. Leatt, A.J. Mouslon, The role of nitrogen flow into the nitriding compact in the production of reaction-sintered silicon nitride, Proc. Brit. Ceram. Soc. 22 (1973) 253-274.

[9] F. Wang, X. Qin, G. Jin, X. Guo, Temperature-controlled synthesis of $\mathrm{Si}_{3} \mathrm{~N}_{4}$ nanomaterials via direct nitridation of Si powders, Physica E 42 (2010) 2033-2035.

[10] M. Maalmi, A. Varma, Intrinsic nitridation kinetics of high-purity silicon powder, AlChe Journal 42 (1996) 3477-3483. 
[11] C.E. Bouldin, E.A. Stern, M.S. Donley, T.G. Stoebe, Iron impurities in $\mathrm{Si}_{3} \mathrm{~N}_{4}$ processing, J. Mater. Sci. 20 (1985) 1807-1810.

[12] W.R. Moser, D.S. Briere, R. Correia, G.A. Rossetti, Kinetics of iron-promoted silicon nitridation, J. Mater. Res. 1 (1986) 797-802.

[13] R.G. Pigeon, A. Varma, Quantitative kinetic analysis of silicon nitridation, J. Mater. Sci. 28 (1993) 2999-3013.

[14] H. Kim, C.H. Kim, The effects of second-component gases on the transport properties of silicon nitriding atmosphere, J. Mater. Sci. Letters 3 (1984) 199-200.

[15] H. Kim, C.H. Kim, The influence of the various transport properties of the nitriding atmosphere on the formation of reaction-bonded $\mathrm{Si}_{3} \mathrm{~N}_{4}$, J. Mater. Sci. 20 (1985) 149-156.

[16] C.C. Liu, J.L. Huang, Effect of the electrical discharge machining on strength and reliability of TiN/Si ${ }_{3} \mathrm{~N}_{4}$ composites, Ceram. Int. 29 (2003) 679-687.

[17] H. Wanbao, Z. Baolin, Z. Hanrui, L. Wenlan, Combustion synthesis of $\mathrm{Si}_{3} \mathrm{~N}_{4}-\mathrm{TiN}$ composite powders, Ceram. Inter. 30 (2004) 2211-2214.

[18] L. Maillé, M.A. Dourges, S. Le Ber, P. Weisbecker, F. Teyssandier, Y. Le Petitcorps, R. Pailler, Study of the nitridation process of TiSi 2 powder, Appl. Surf. Sci. 260 (2006) 2931.

[19] J. Roger, L. Maillé, M-A. Dourges, Effect of temperature and grain size on $\mathrm{TiSi}_{2}$ nitridation, ICCM19 proceeding, (2013) p2653-2660.

[20] J.M. Córdoba, M.D. Alcalá, M.J. Sayagués, M.A. Avilés, C. Real, F.J. Gotor, Nitriding study of titanium silicide intermetallics obtained by mechanical alloying, Intermetallics $16(2008) 948-954$.

[21] M. Wittmer, Self-aligned diffusion barrier by nitridation of $\mathrm{TiSi}_{2}$, Appl. Phys. Lett. 52 (1988) 1573-1575. 
[22] J. Perez-Rigueiro, C. Jimenez, L. Vazquez, R. Perez-Casero, J.M. Martinez-Duart, Nitridation of $\mathrm{TiSi}_{2}$ thin films by rapid thermal processing, Surf. Coat. Technol. 80 (1996) 72-75.

[23] A. Kamgar, F.A. Baiocchi, A.B. Emerson, T.T. Sheng, M.J. Vasile, R.W. Haynes, Selfaligned TiN barrier formation by rapid thermal nitridation of $\mathrm{TiSi}_{2}$ in ammonia, J. Appl. Phys. 66 (1989) 2395-2401.

[24] X. Ma, C. Li, W. Khang, The thermodynamic assessment of the Ti-Si-N system and the interfacial reaction analysis, J. Alloys Compd. 394 (2005) 138-147.

[25] F.W. Chang, T.H. Liou, F.M. Tsai, The nitridation kinetics of silicon powder compacts, Thermochimica Acta 354 (2000) 71-80.

[26] D. Kusano, Effects of impurity iron content on characteristics of sintered reactionbonded silicon nitride, Int. J. Appl. Ceram. Technol. 10 (2013) 690-700.

[27] R.G. Pigeon, A. Varma, Quantitative phase analysis of $\mathrm{Si}_{3} \mathrm{~N}_{4}$ by X-ray diffraction, J. Mater. Sci. Lett. 11 (1992) 1370-1372.

[28] H.M. Rietveld, A profile refinement method for nuclear and magnetic structures, J. Appl. Crystallogr. 2 (1969) 65-71.

[29] J. Rodriguez-Carvajal, Recent advances in magnetic structure determination by neutron powder diffraction, Physica B 192 (1993) 55-69.

[30] A. Atkinson, A.J. Moulson, E.W. Roberts, Nitridation of high-purity silicon, J. Am. Ceram. Soc. 59 (1976) 285-289.

[31] R.G. Pigeon, A. Varma, A.E. Miller, Some factors influencing the formation of reactionbonded silicon nitride, J. Mater. Sci. 28 (1993) 1919-1936.

[32] R. Pompe, L. Hermansson, Characterization of silicon powders for the production of $\mathrm{Si}_{3} \mathrm{~N}_{4}$, Mater. Sci. Eng. 71 (1985) 355-362. 
[33] B.W. Sheldon, J. Szekely, J.S. Haggerty, Formation of reaction-bonded silicon nitride from silane-derived silicon powders: macroscopic kinetics and related transport phenomena, J. Am. Ceram. Soc. 75 (1992) 677-685.

[34] A. Khawam, D.R. Flanagan, Solid-State Kinetic Models: Basics and Mathematical Fundamentals, J. Phys. Chem. B 110 (2006) 17315-17328.

[35] A.K. Galwey, M.E. Brown, Thermal decomposition of ionic solids, Amsterdam, Elsevier, 1999, pp. 75-110.

[36] ICTAC Kinetics Committee recommendations for performing kinetic computations on thermal analysis data, S. Vyazovkina, A.K. Burnhamb, J.M. Criadoc, L.A. PérezMaquedac, C. Popescud, N. Sbirrazzuolie, Thermochimica Acta 520 (2011) 1-19.

[37] M. Avrami, Granulation, phase change and microstructure: Kinetics of phase change (III), J. Chem. Phys. 9 (1941) 177-184.

[38] W.A. Johnson, P.A. Mehl, Reaction kinetics in processes of nucleation and growth, Trans. Am. Inst. Metall. Pet. Eng. 135 (1939) 416-458.

[39] J.P. Braganti, O. Held, F.A. Kuhnast, E. Illekov, Kinetic study of isothermal crystallization in amorphous $\mathrm{Al}_{33} \mathrm{Ni}_{16} \mathrm{Zr}_{51}$ produced by mechanical alloying, Thermochimica Acta 362 (2000) 71-78.

[40] M.A. Bab, L. Mendoza-Zélis, L.C. Damonte, Nanocrystalline HfN producted by mechanical milling: kinetic aspects, Acta Mater. 49 (2001) 4205-4213

[41] J. Malek, The applicability of Johnson-Mehl-Avrami model in the thermal analysis of the crystallization kinetics of glasses, Thermochimica Acta 267 (1995) 61-73.

[42] J.W. Christian, The theory of transformation in metals and alloys. Oxford (UK): Elsevier Ltd., 2002.

[43] A. Narlikar, Studies of high temperature superconductors: Advances in research and applications. Nova Publishers, Technology \& Engineering, 2001, pp.48. 
[44] Y. Shen, H.H. Hng, J.T. Oh, Formation kinetics of Ni-15\%Fe-5\%Mo during ball milling. Mater. Lett. 58 (2004) 2824-2828.

[45] H. Sheu, L. Hsiung, J. Sheu, Synthesis of multiphase intermetallic compounds by mechanical alloying in Ni-Al-Ti system, J. Alloys Compds. 469 (2009) 483-487.

[46] L.E. Levine, K. Lakshmi Narayan, K.F. Kelton, Finite size corrections for the JohnsonMehl-Avrami-Kolmogorov equation, J. Mater. Res. 12 (1997) 124-132.

[47] C. Suryanarayana, E. Ivanov, V.V. Boldyrev, The science and technology of mechanical alloying, Mater. Sci. Eng. A304-306 (2001) 151-158.

[48] S. Sheibani, A. Ataie, S. Heshmati-Manesh, Kinetics analysis of mechano-chemically and thermally synthesized $\mathrm{Cu}$ by Johnson-Mehl-Avrami model, J. Alloys Compds. 455 (2008) 447-453. 


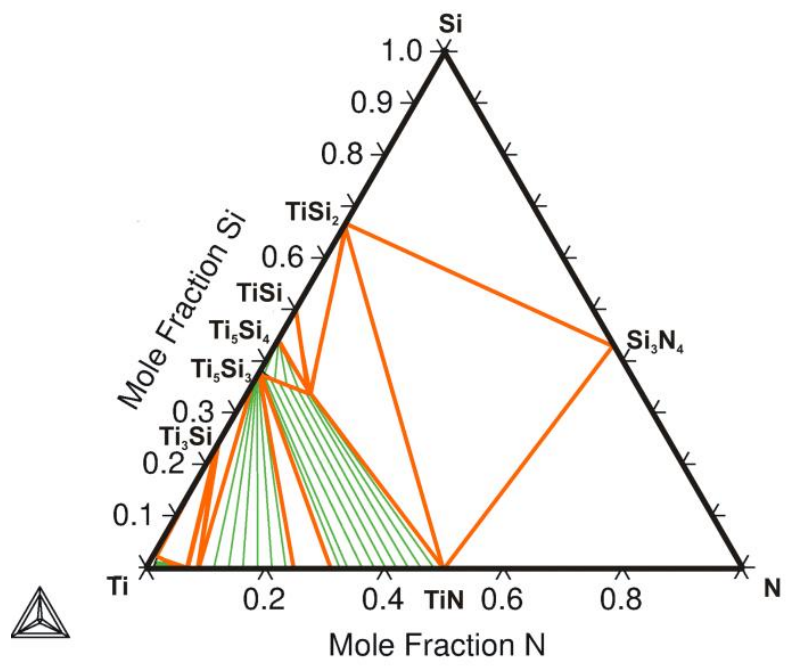

Figure 1. Calculated isothermal Ti-Si-N diagram at $1373 \mathrm{~K}$ [24].

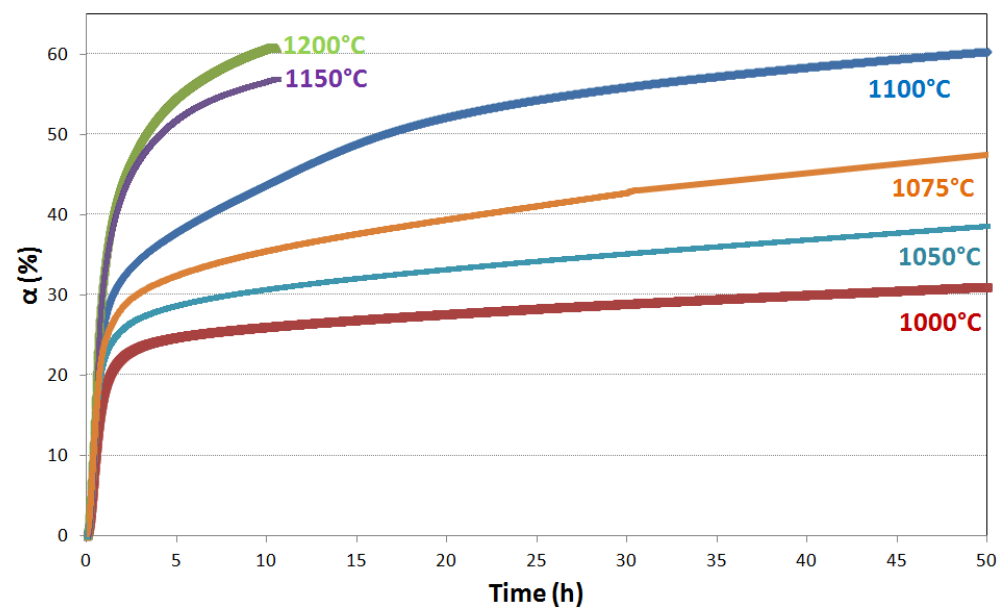

Figure 2. Mass conversion degree of reaction of the powder with $\mathrm{d}_{50}=1.4 \mu \mathrm{m}$ for nitridation time up to 50 hours at temperatures between 1000 and $1200^{\circ} \mathrm{C}$.

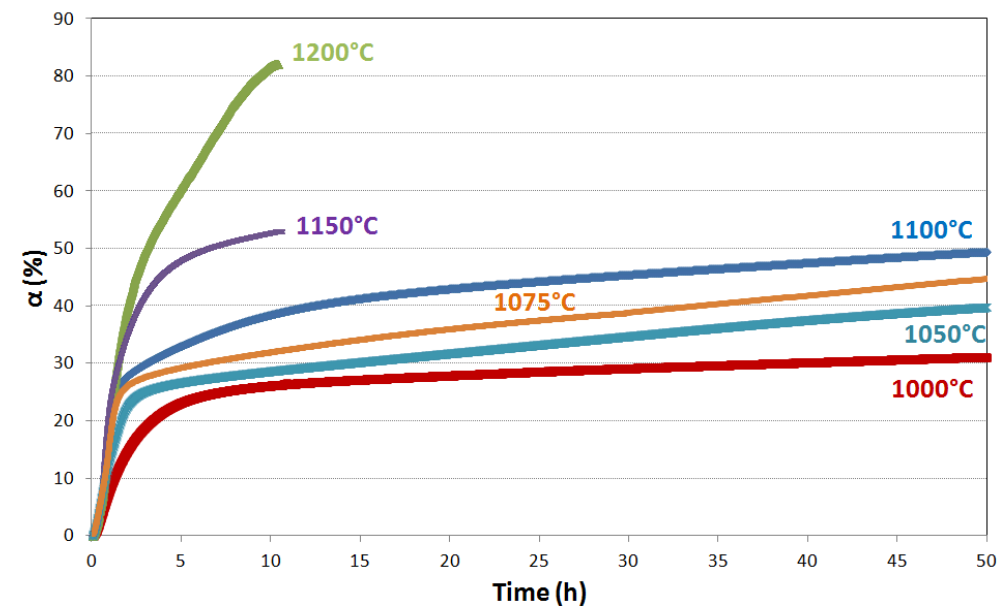

Figure 3. Mass conversion degree of reaction of the powder with $\mathrm{d}_{50}=4.5 \mu \mathrm{m}$ for nitridation time up to 50 hours at temperatures between 1000 and $1200^{\circ} \mathrm{C}$. 


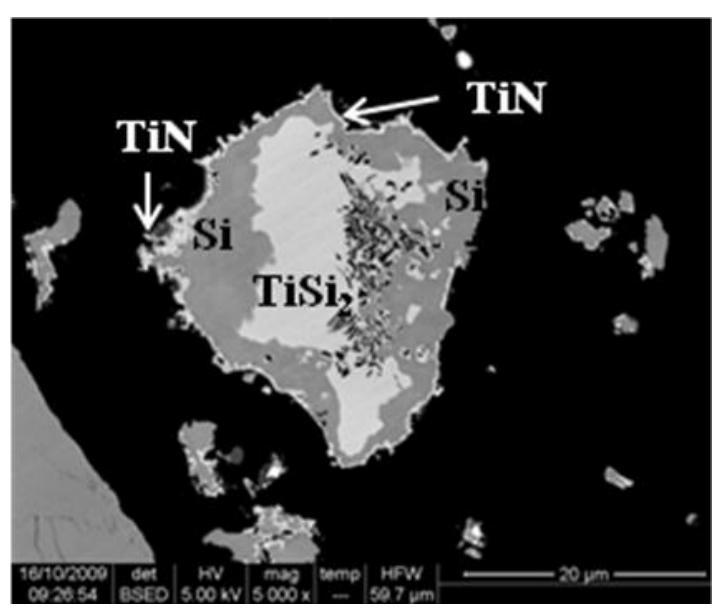

a)

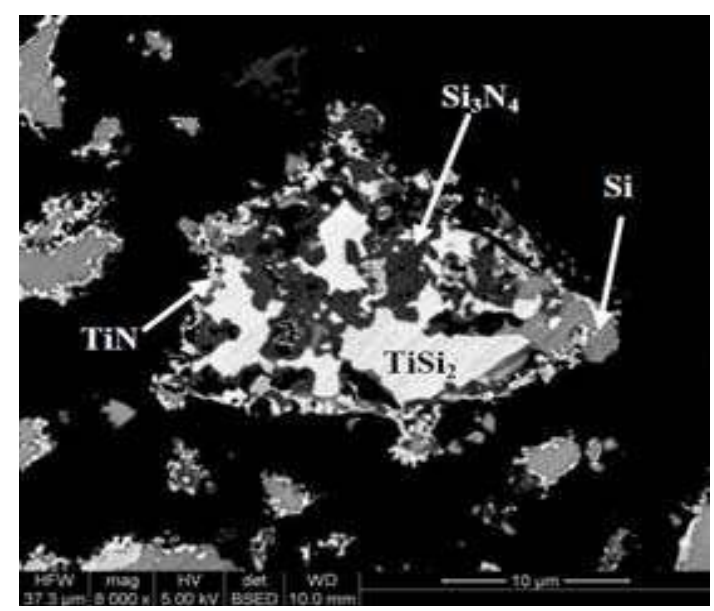

b)

Figure 4. Backscattered electrons image of a transverse $\mathrm{TiSi}_{2}$ grain nitrurated at $1100^{\circ} \mathrm{C}$ :

a) during $5 \mathrm{~h}, \mathrm{~b}$ ) during $50 \mathrm{~h}$.

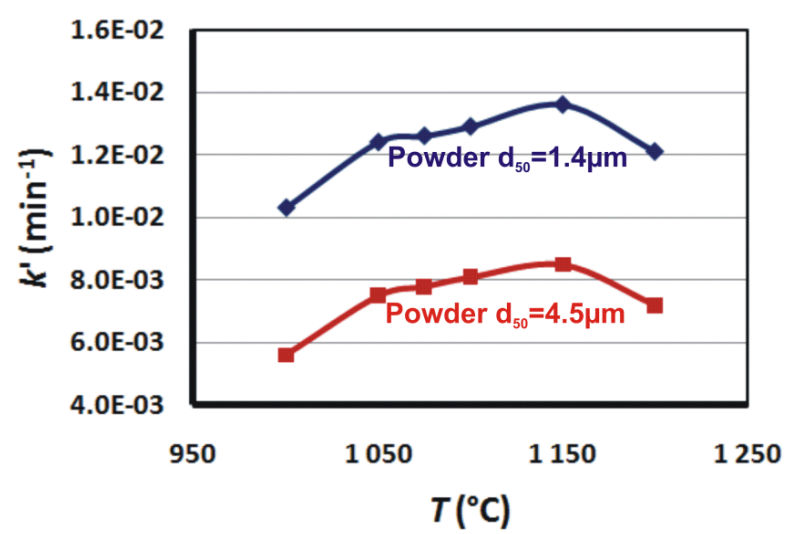

Figure 5. Plots of $k^{\prime}$ coefficients versus temperature for the two powders between 1000 and $1200^{\circ} \mathrm{C}$.

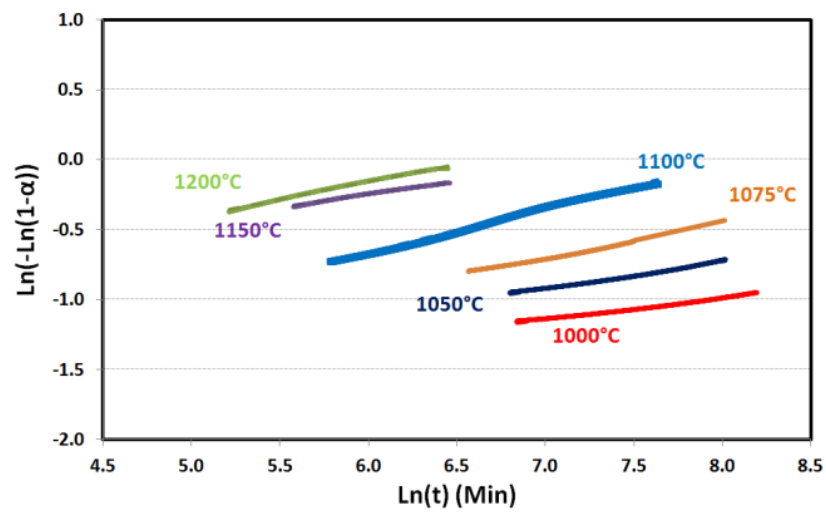

a)

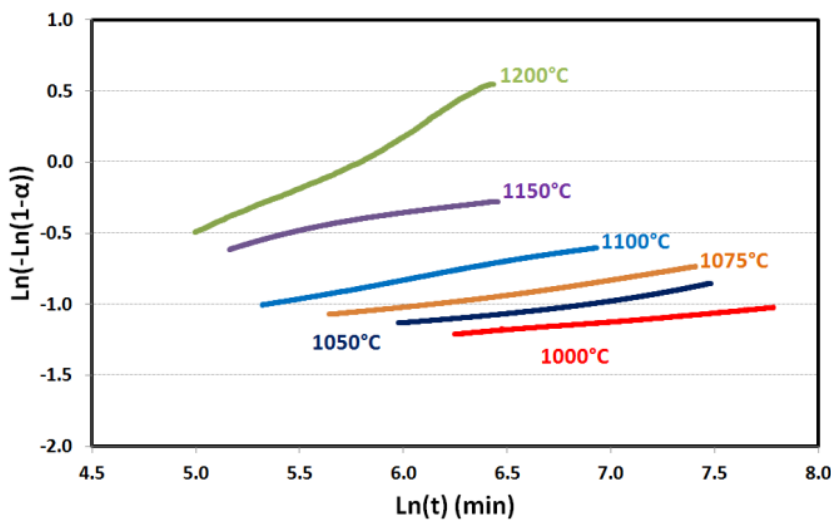

b)

Figure 6. Avrami plot of $\operatorname{Ln}[-\operatorname{Ln}(1-\alpha)]$ versus $\operatorname{Ln}(t)$ for the powder between 1000 and $1200^{\circ} \mathrm{C}$ with a) $\mathrm{d}_{50}=1.4 \mu \mathrm{m}$ and b) $\mathrm{d}_{50}=4.5 \mu \mathrm{m}$. 


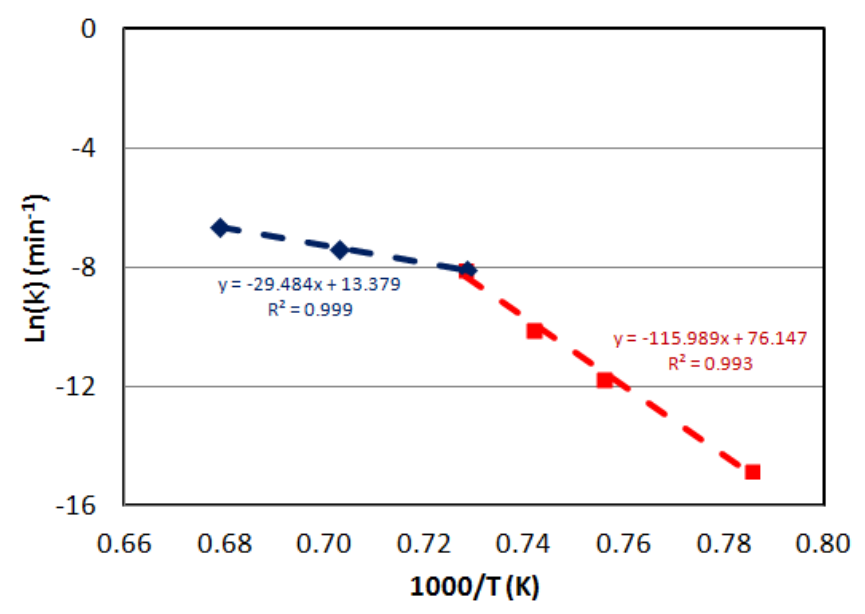

a)

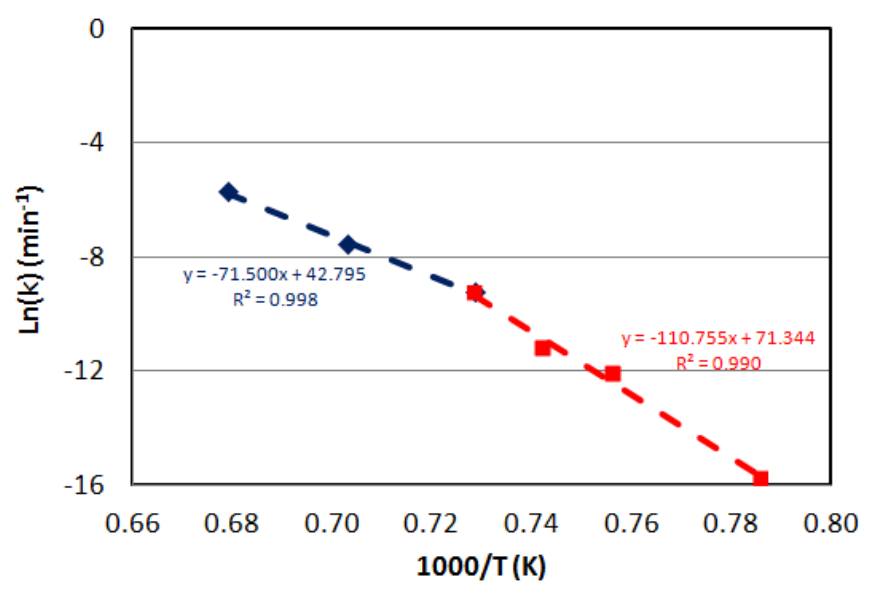

b)

Figure 7. Arrhenius plot $\operatorname{Ln}(k)=f(1000 / T)$ for nitridation of the powder between 1000 and $1200^{\circ} \mathrm{C}$ with a) $d_{50}=1.4 \mu \mathrm{m}$ and b) $d_{50}=4.5 \mu \mathrm{m}$. The blue and red dotted lines are the linear fits of the two behaviors.

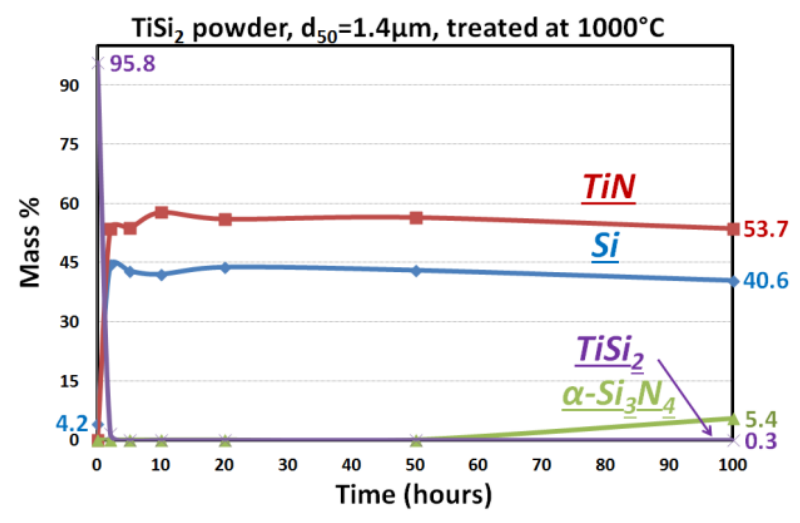

a)

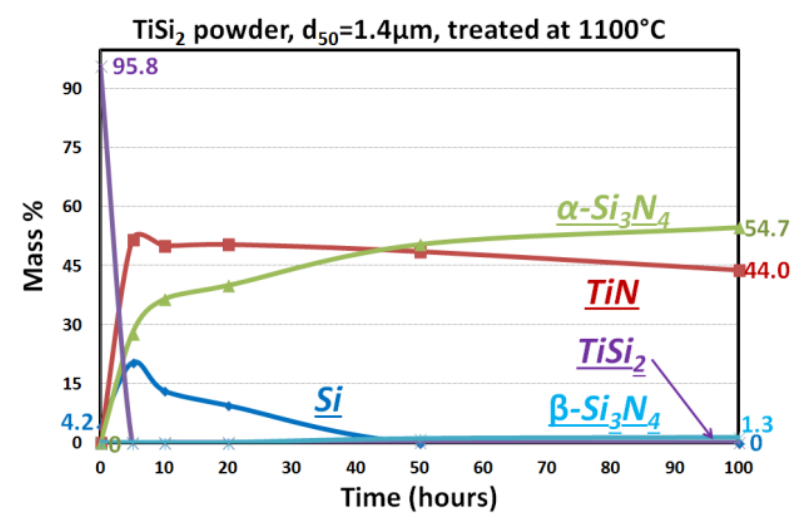

c)

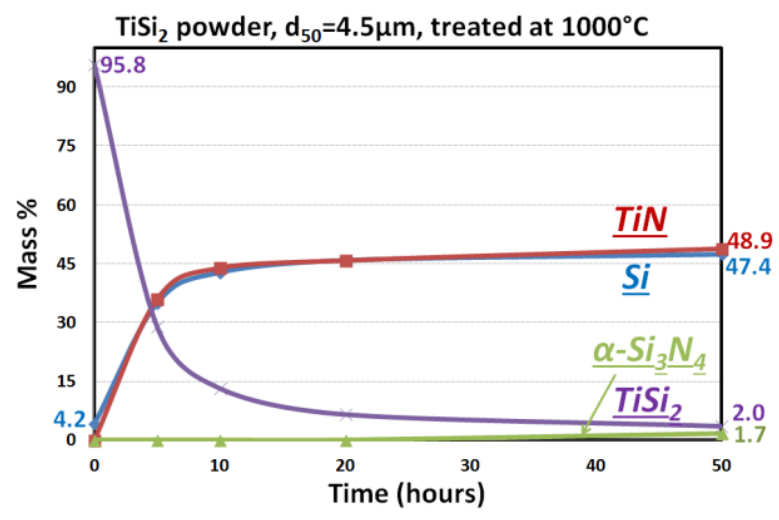

b)

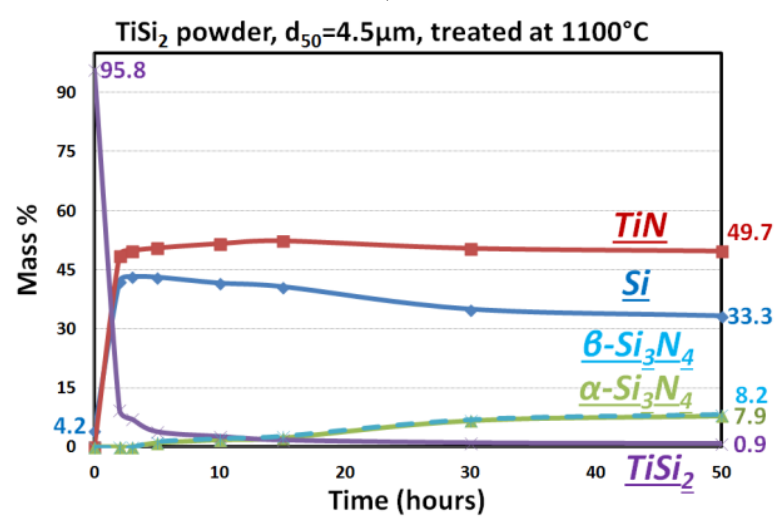

d)

Figure 8. Phases quantifications by Rietveld method during nitridation of $\mathrm{TiSi}_{2}$ powders: a) powder with $\mathrm{d}_{50}=1.4 \mu \mathrm{m}$ at $1000^{\circ} \mathrm{C}$, b) powder with $\mathrm{d}_{50}=4.5 \mu \mathrm{m}$ at $1000^{\circ} \mathrm{C}$, c) powder with $\mathrm{d}_{50}=1.4 \mu \mathrm{m}$ at $1100^{\circ} \mathrm{C}, \mathrm{d}$ ) powder with $\mathrm{d}_{50}=4.5 \mu \mathrm{m}$ at $1100^{\circ} \mathrm{C}$. 


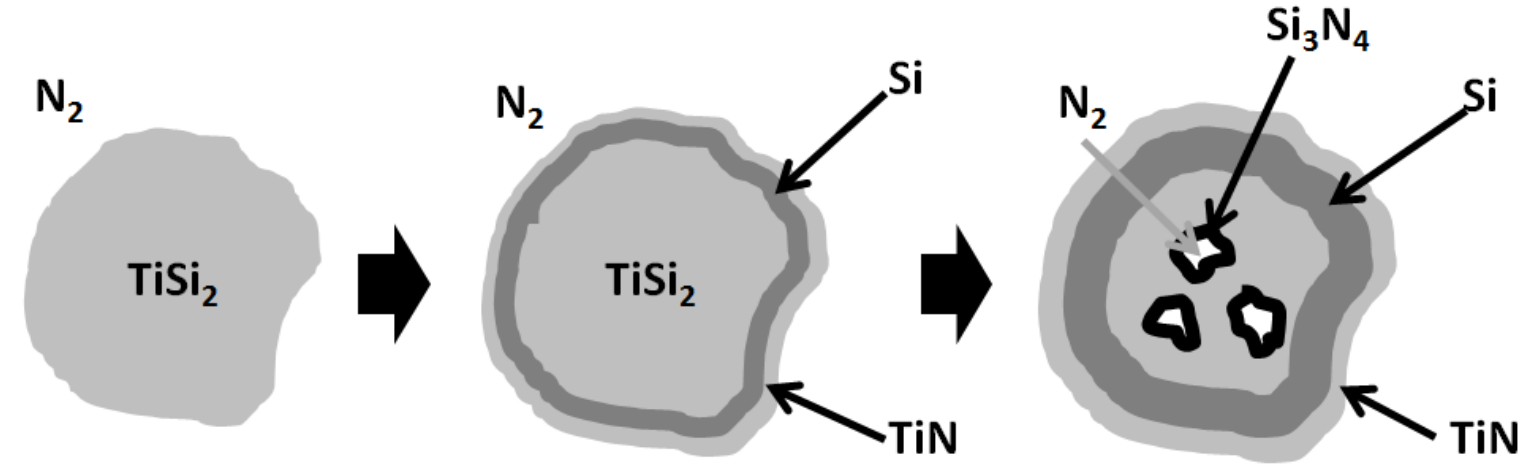

Figure 9. Schematic representation of the three main stages of the conversion: at the beginning $\mathrm{TiSi}_{2}$ powder is in presence of gaseous nitrogen, then nitrogen reacts with titanium atoms to form a layer of $\mathrm{TiN}$ at the surface of the grain by generating a silicon sublayer. Owing to Kirkendall effect, porosities appear within the grain. $\mathrm{Si}_{3} \mathrm{~N}_{4}$ is formed at the surface of the porosities. 
Table 1. Values of the mass conversion rate $\alpha$ for the two powders with mean grain sizes of 1.4 and $4.5 \mu \mathrm{m}$ after 10 hours of nitridation at $1000,1050,1100,1150$ and $1200^{\circ} \mathrm{C}$.

$\mathrm{T}\left({ }^{\circ} \mathrm{C}\right)$

\begin{tabular}{lccccccc} 
& $\begin{array}{c}\text { Mean grain } \\
\text { size }\left(d_{50}\right)\end{array}$ & 1000 & 1050 & 1075 & 1100 & 1150 & 1200 \\
\hline $\boldsymbol{\alpha ( \% )}$ & $\mathbf{1 . 4 \mu \mathrm { m }}$ & 25.7 & 30.1 & 34.5 & 41.8 & 55.5 & 59.1 \\
$( \pm \mathbf{1 \% )}$ & $\mathbf{4 . 5 \mu \mathrm { m }}$ & 25.7 & 28.1 & 31.0 & 36.9 & 51.6 & 76.2 \\
\hline
\end{tabular}

Table 2. Calculated values of nitridation kinetics parameters $(k, n)$ and of the corresponding reliability factors $\left(R^{2}\right)$ for the two powders between 1000 and $1200^{\circ} \mathrm{C}$.

\begin{tabular}{c|ccc|ccc}
\cline { 2 - 6 } & \multicolumn{2}{c}{ Powder with $\mathrm{d}_{50}=1.4 \mu \mathrm{m}$} & \multicolumn{3}{c}{ Powder with $\mathrm{d}_{50}=4.5 \mu \mathrm{m}$} \\
\hline $\boldsymbol{T}\left({ }^{\circ} \mathrm{C}\right)$ & $\boldsymbol{k}\left(\mathrm{min}^{-1}\right)$ & $n$ & $\boldsymbol{R}^{2}$ & $k\left(\mathrm{~min}^{-1}\right)$ & $n$ & $\boldsymbol{R}^{2}$ \\
\hline $\mathbf{1 0 0 0}$ & $3.66 \times 10^{-7}$ & 0.150 & 0.992 & $1.47 \times 10^{-7}$ & 0.125 & 0.997 \\
\hline $\mathbf{1 0 5 0}$ & $7.90 \times 10^{-6}$ & 0.195 & 0.991 & $5.77 \times 10^{-6}$ & 0.191 & 0.979 \\
\hline $\mathbf{1 0 7 5}$ & $4.23 \times 10^{-5}$ & 0.230 & 0.994 & $1.45 \times 10^{-5}$ & 0.200 & 0.992 \\
\hline $\mathbf{1 1 0 0}$ & $3.08 \times 10^{-4}$ & 0.317 & 0.995 & $9.75 \times 10^{-5}$ & 0.257 & 0.998 \\
\hline $\mathbf{1 1 5 0}$ & $6.35 \times 10^{-4}$ & 0.188 & 0.995 & $5.29 \times 10^{-4}$ & 0.237 & 0.975 \\
\hline $\mathbf{1 2 0 0}$ & $1.32 \times 10^{-3}$ & 0.252 & 0.996 & $3.35 \times 10^{-3}$ & 0.765 & 0.989 \\
\hline
\end{tabular}

Table 3. Apparent activation energies of nitridation for the two powders between 1000 and $1200^{\circ} \mathrm{C}$.

$$
\text { Activation energy } E_{a}\left(\mathrm{~kJ} . \mathrm{mol}^{-1}\right)
$$

\begin{tabular}{ccc}
\hline Temperature range & $1000-1100^{\circ} \mathrm{C}$ & $1100-1200^{\circ} \mathrm{C}$ \\
\hline Powder with & 964 & 245 \\
$d_{50}=1.4 \mu \mathrm{m}$ & & \\
\hline Powder with & 921 & 594 \\
$d_{50}=4.5 \mu \mathrm{m}$ & & \\
\hline
\end{tabular}


Table 4. Frequency factors of nitridation for the two powders between 1000 and $1200^{\circ} \mathrm{C}$.

\section{Frequency factor $k_{0}\left(\mathrm{~min}^{-1}\right)$}

\begin{tabular}{ccc}
\hline Temperature range & $1000-1100^{\circ} \mathrm{C}$ & $1100-1200^{\circ} \mathrm{C}$ \\
\hline Powder with & $1.18 \times 10^{33}$ & $6.46 \times 10^{5}$ \\
$\mathbf{d}_{50}=1.4 \mu \mathrm{m}$ & & $3.85 \times 10^{18}$ \\
\hline Powder with & $9.65 \times 10^{30}$ & \\
$\mathbf{d}_{50}=4.5 \mu \mathrm{m}$ & & \\
\hline
\end{tabular}

